\title{
ELEMENTOS PRELIMINARES PARA A CONSTRUÇÃO DE MODELOS: A CONTIBUIÇÃO DA GESTÃO DO CONHECIMENTO PARA INSTITUIÇÕES DE ENSINO SUPERIOR
}

\section{PRELIMINARY ELEMENTS FOR THE CONSTRUCTION OF MODELS: THE CONTRIBUITION OF KNOWLEDGE MANAGEMENT TO TERTIARY EDUCATION INSTITUITIONS}

\author{
Joyce Lene Gomes Cajueiro ${ }^{1}$; Abraham Benzaquen Sicsú ${ }^{2}$; Ana Regina Bezerra Ribeiro ${ }^{3}$ \\ ${ }^{1}$ Universidade Federal de Pernambuco, Centro Acadêmico do Agreste - UFPE - Caruarú - Brasil \\ joyce.cajueiro@hotmail.com \\ ${ }^{2}$ Fundação Joaquim Nabuco e Universidade Federal de Pernambuco FUNDAJ, UFPE- Recife \\ Brasil \\ sicsu@fundaj.gov.br \\ ${ }^{3}$ Faculdade Marista Recife - FMR - Recife - Brasil \\ arbr@hotmail.com
}

\begin{abstract}
Resumo
O conhecimento é, atualmente, um fator imprescindivel para a sobrevivência e sucesso das organizações. Pesquisadores têm desenvolvido estudos que resultam na elaboração de conceitos, sistemas e modelos de Gestão de Conhecimento que agregam valor aos produtos e serviços oferecidos, bem como em aumentar a eficiência das organizações, tornando-as mais competitivas. Este artigo, realizado a partir de uma pesquisa de natureza exploratória, introduz a definição de Gestão do Conhecimento e pretende identificar indícios que revelem a existência de elementos que fazem parte do processo de Gestão de Conhecimento e colaborem para a melhoria da qualidade de ensino e aumento de produtividade. Também propõe investigar as características de alguns modelos de Gestão de Conhecimento no contexto acadêmico e suas peculiaridades, fazer uma análise comparativa entre alguns deles, assim como originar uma perspectiva que contribua para a criação de um novo modelo de Gestão de Conhecimento para Instituições de Ensino Superior.
\end{abstract}

Palavras-chave: gestão do conhecimento; análise de modelos; instituições de ensino superior.

\section{Introdução}

O conhecimento tornou-se o bem mais precioso, inclusive nas organizações, que buscam o aproveitamento do conhecimento, através de tecnologias e práticas a fim da consecução de seus objetivos e a obtenção de vantagem competitiva diante dos concorrentes. Atualmente o conhecimento se transformou no principal fator de produção, o trabalhador tem que lidar com diversos ramos do conhecimento, ser inovador e pro ativo. 
Muitas organizações têm como estratégia para aumentar a competitividade, a utilização dos bens intelectuais da organização em prol da melhoria da qualidade dos produtos e serviços oferecidos. A soma dos conhecimentos individuais agrega um valor maior para a organização, o que reflete num aumento na produtividade. Surge, então, a necessidade de gerenciar o conhecimento das pessoas de uma organização para que os resultados sejam realmente positivos. Planejar uma estratégia orientada para a mudança e inovação possibilita novas oportunidades que são viabilizadas através da Gestão do Conhecimento.

Atualmente a Gestão do Conhecimento tem sido foco dos estudiosos da administração. As pesquisas e aplicações geralmente acontecem no âmbito empresarial, voltadas para a perspectiva da Aprendizagem Organizacional e Gestão do Conhecimento Organizacional. A maioria dos conceitos de Gestão de Conhecimento encontrados na literatura é referente ao conhecimento organizacional. São raras as iniciativas de desenvolvimento de gestão do conhecimento no ambiente acadêmico, nas atividades de pesquisa e ensino, embora seja possível encontrar alguma literatura a respeito, a sua maioria é sob a perspectiva da tecnologia da informação.

Neste contexto, é imprescindível o desenvolvimento de uma pesquisa para incrementar a criação e o compartilhamento do conhecimento através do estudo dentro da comunidade acadêmica. O objetivo deste artigo é fazer um levantamento de alguns estudos desenvolvidos em Gestão de Conhecimento, principalmente em modelos existentes no contexto acadêmico para analisar e identificar elementos imprescindíveis para criação e funcionamento de um modelo nesta área que, por sua vez, torne a organização de ensino eficiente para que ela desenvolva suas atividades de criação, transferência, disseminação do conhecimento de forma competitiva.

Dentre os estudos realizados sobre Gestão do Conhecimento no contexto acadêmico, está a pesquisa de Felix (2003), que em sua dissertação de mestrado, analisa a literatura sobre o tema e ressalta vários elementos importantes para a construção de modelos de Gestão de Conhecimento para Instituições de ensino Superior. Os modelos desenvolvidos por Felício Júnior (2002) e Leite (2006) também trazem contribuições consideráveis para o tema.

Os autores consideram que, devido à turbulência do ambiente, há necessidade de se antecipar às mudanças e também, ressaltam a importância de gerenciar o conhecimento nas organizações. As Instituições de Ensino superior são organizações responsáveis pela criação e distribuição de conhecimento, portanto, instituições formadoras de profissionais qualificados para desenvolverem atividades na sociedade que vive em mudança constante.

O meio ambiente determina o grau de incerteza e de dependência que a organização enfrenta. Ambientes turbulentos requerem uma atenção maior, então os administradores precisam monitorar o ambiente e tentar prever o que poderia afetar a organização, assim como quais as estratégias para se ajustar a tal ambiente. A globalização tornou o trabalho do administrador 
desafiador devido ao aumento da competitividade e pressões geradas pelas oportunidades e ameaças do mercado, onde o ambiente é muito turbulento e exige que as pessoas e organizações estejam sempre atentas para não correrem o risco de ficarem obsoletas, seja em relação aos métodos, às técnicas ou às tecnologias aplicadas pelos concorrentes. Todos estes fatores têm contribuído para que haja uma preocupação, por parte das instituições de ensino superior, com a formação dos administradores de empresa, e a Gestão do Conhecimento pode colaborar de forma positiva para resolver esta questão.

\section{Instituições de ensino superior e ambiente turbulento: uma abordagem sistêmica para a formação de administradores de empresa}

Segundo Maximiano (2004), os conhecimentos administrativos são produzidos pela observação e análise crítica da experiência prática das organizações e seus administradores. Há duas fontes principais desses conhecimentos: a experiência prática e os métodos científicos. $\mathrm{O}$ conhecimento sempre volta para o mundo que o produziu, num processo de constante elaboração, conforme figura1, abaixo.

Figura.1 : Processo de formação e disseminação das teorias da administração

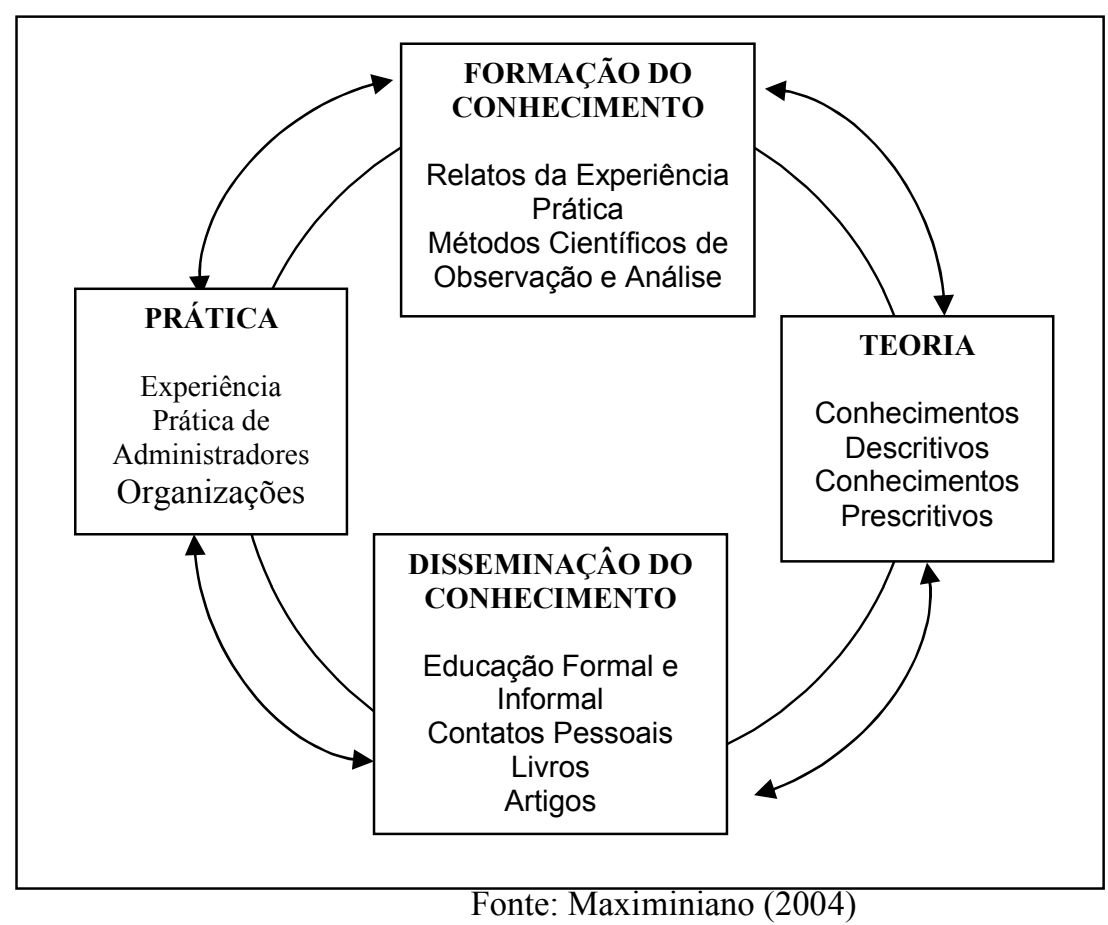

Desde o início do mercantilismo com a chegada da revolução industrial, criou-se uma demanda por conceitos e técnicas para serem utilizadas pelo administrador, surgiu o interesse pela aplicação de conhecimentos administrativos, a administração começou a se consolidar como uma 
área de conhecimento e surgiram modelos de administração relatando experiências vividas pelo administrador que, na época, trabalhava nas fábricas.

As contribuições teóricas de estudiosos que refletem e registram sua própria experiência. A transmissão dos conhecimentos empíricos, assim como a existência de organizações, é antiga, há muito tempo os administradores possuem um acervo de conhecimentos que crescem e se tornam mais requintados com o passar do tempo.

Teoria é representação abstrata do que se percebe como realidade. Um conjunto de informações ou regras feitas para enquadrar alguma parte do mundo real (ZIMBARDO e EBBESEN, 1970).

Vivemos numa época de mudanças, incertezas e complexidades, na qual a administração é uma das áreas mais importantes das atividades humanas. $\mathrm{O}$ trabalho do administrador é uma das carreiras mais estimulantes e gratificantes, não só pelos desafios que proporciona, mas porque promove a satisfação aos indivíduos que realizam estas atividades, e ainda propicia grandes contribuições à sociedade. Através do trabalho podem-se realizar grandes projetos em organizações, sejam elas empresas privadas, hospitais, universidades, e até organizações não lucrativas. O administrador envolve-se em atividades diversas, organizando equipes a fim de alcançarem os objetivos pessoais e das organizações, consequentemente, podem criar soluções para problemas do mundo moderno.

Nas últimas décadas as organizações estão utilizando em suas práticas a abordagem sistêmica, que vê a organização como um sistema unificado composto de várias partes relacionadas entre si e com o meio na qual está inserida, ou seja, permite que a organização seja vista como um todo e que também faz parte de um sistema maior que é o ambiente externo. A organização é um sistema aberto que interage com seu ambiente, desta forma, as atividades de uma organização influenciam e são influenciadas pelo ambiente. As entradas são os insumos que interferem e contribuem para o processo de transformação e fabricação de produtos e serviços são os fluxos vindos do ambiente tais como os recursos humanos, financeiros, tecnológicos e informações. Por outro lado, as saídas são os bens e serviços desenvolvidos para serem oferecidos para a sociedade.

Atualmente o ambiente passa por mudanças contínuas e rápidas que influenciam inclusive nas estratégias administrativas. Novas tecnologias, investimento em pesquisa e desenvolvimento e as mudanças no estilo de vida dos consumidores, pressionam cada vez mais o administrador a prever e atender essas exigências das forças externas, no sentido de pensar globalmente, considerando as variáveis sociais, econômicas tecnológicas e políticas.

Há elementos do meio ambiente que influenciam diretamente nas atividades de uma organização, tais como os sindicatos, fornecedores, competidores, consumidores, grupos de interesses especiais e órgãos governamentais, assim como os empregados e acionistas. 
As instituições de ensino superior fazem parte do universo das organizações, estão inseridas neste ambiente e, portanto sofrem a influência do mesmo, e exercem sua influência através da criação do conhecimento. O conhecimento é o bem intangível de maior valor em uma organização, e é formado pela parte tácita inerente ao ser humano, que muitas vezes torna-se explícita em normas. São informações atualizadas, as experiências obtidas ao longo do tempo, as tendências futuras, e intuições que formam as competências essenciais. Segundo Murray (2005), é importante usar uma estratégia que transforme bens intelectuais da organização em maior produtividade, valores e competitividade.

As instituições de ensino superior são organizações que participam ativamente para transformar a sociedade em sociedade do conhecimento. Atualmente, na era do conhecimento, a aprendizagem faz parte do processo de produção. Segundo Buarque (1994), a universidade proporcionou à humanidade um grande avanço, ao conseguir fazer o pensamento sair dos dogmas da revelação divina e descobrir a possibilidade da certeza das descobertas científicas. $\mathrm{O}$ ensino universitário tem-se dado, sobretudo pela transmissão das certezas. As dúvidas parecem ser desenvolvidas no exterior, e penetram na universidade depois de solucionadas em uma nova certeza de que os professores transmitem aos alunos, e estes mostram ter aprendido, repetindo-a nas provas. A transgressão exige um método novo. Só a constante prática da dúvida permitirá o avanço do conhecimento. É preciso contestar todas as teorias, todas as formulações e premissas, na busca de novos conhecimentos. E esta contestação deve estar no método de pesquisa, de ensino e de avaliação.

As transformações sociais, tecnológicas e econômicas são dinâmicas e fazem com que as Instituições de Ensino Superior corram o risco de se tornarem obsoletas e de perderem a eficiência no desempenho de sua função maior, que é atender as necessidades da sociedade em um ambiente turbulento. É preciso acompanhar o ambiente e fazer uma constante avaliação dos métodos de criação, transferência e gerenciamento do conhecimento.

Analisando-se a abordagem de um ambiente de ensino e da Gestão do Conhecimento, podese considerar que ambos têm como base o ensino-aprendizagem e que a Gestão do Conhecimento pode ser vista, potencialmente, como um processo que auxilia na maximização da área pedagógica de uma escola, uma vez que sua teoria se baseia na hipótese de que quanto maior a troca de conhecimentos, mais a amplia (VON KROGH, 2001).

A Gestão do Conhecimento é usada como estratégia para que as organizações possam se adaptar e até mesmo se antecipar às mudanças aceleradas que estão ocorrendo no mundo. Planejar uma estratégia orientada para a mudança, inovação e reorganização da organização possibilita a abertura de novos caminhos, novas oportunidades que são viabilizadas através da Gestão do Conhecimento. 


\section{Gestão do Conhecimento: conceitos e peculiaridades}

A importância do conhecimento para as organizações fez surgir o interesse pelo gerenciamento desse ativo tão valioso, por isso, muitos estudiosos têm se dedicado ao tema de forma a destacar a sua significância. Gestão do Conhecimento é uma maneira sistemática de perceber os conhecimentos existentes na organização e como aproveitar o potencial em seu beneficio. A Gestão do Conhecimento considera o conhecimento existente na organização, a sua transferência para os demais membros, assim como, a criação de novos conhecimentos.

A literatura descreve Gestão do Conhecimento no ambiente organizacional em diferentes focos: a cultura organizacional, relações entre as pessoas de áreas, níveis e empresas diferentes, o desenvolvimento das competências essenciais para a organização, mapeamento, codificação e compartilhamento do conhecimento organizacional, os avanços da informática e o valor do capital intelectual da organização.

Segundo Terra (2005), Gestão do Conhecimento significa organizar as principais políticas, processos e ferramentas gerenciais e tecnológicas à luz de uma melhor compreensão dos processos de geração, identificação, validação, disseminação, compartilhamento e uso dos conhecimentos estratégicos para gerar resultados (econômicos) para a empresa e benefícios para os colaboradores.

Para Wiig (1993) Gestão do Conhecimento é a construção sistemática, explícita e intencional do conhecimento e a sua aplicação para maximizar a eficiência e o retorno sobre os ativos de conhecimento da organização. Segundo Petrash (1996) Gestão do Conhecimento é a disponibilização do conhecimento certo para as pessoas certas, no momento certo, de modo que estas possam tomar as melhores decisões para a organização. Já para Hibbard (1997) Gestão do Conhecimento é conceituado como um processo de busca e organização da expertise coletiva da organização, em qualquer lugar em que se encontre, e de sua distribuição para onde houver maior retorno. No entanto, para Beckman (1999), Gestão do Conhecimento é a formalização das experiências, conhecimentos e expertise, de forma que se tornem acessíveis para a organização, e esta possa criar novas competências, alcançar desempenho superior, estimular a inovação e criar valor para seus clientes. E para finalizar, Nonaka e Takeuchi (1997) conceituam a Gestão do Conhecimento como a atividade de divulgar e explicitar os saberes implícitos nas práticas individuais e coletivas das organizações.

A maioria das definições de Gestão de Conhecimento envolve os conceitos de conhecimento explícito e tácito de Nonaka e Takeuchi (1997). O conhecimento explícito pode ser transmitido por linguagem formal e representa apenas uma parte do conhecimento existente, enquanto o conhecimento tácito pode ser transmitido através de um exemplo. O conhecimento é gerado a partir dos processos de socialização, combinação, externalização e internalização. 
Segundo Nonaka (2000), a empresa criadora de conhecimento tem os quatro padrões de criação de conhecimento (socialização, internalização, externalização e combinação) que estão em constante interação dinâmica constituindo a espiral do conhecimento. Primeiro a organização aprende os segredos tácitos dos funcionários, em seguida converte estes segredos em conhecimento explícito transferíveis a vários membros da organização. A equipe padroniza esse conhecimento, compilando - o em manual e incorporando a um novo produto ou serviço. E, finalmente, a equipe enriquece o conhecimento tácito e o compreendem como a maneira intuitiva, e percebem como se dá a criação e desenvolvimento do conhecimento, através da internalização.

Tanto a internalização quanto a externalização são fases críticas da espiral porque exigem o envolvimento das pessoas. Ao criar um novo conhecimento, as pessoas estão se renovando, inovando uma situação, renovando a si mesmo assim como a empresa onde trabalha.

Apesar dos elementos que envolvem a infra-estrutura, tecnologia, processos, comunicação e sistemas administrativos, na Gestão do Conhecimento, as pessoas são consideradas como questão principal a ser desenvolvida. O objetivo da Gestão do Conhecimento é propagação do conhecimento entre as pessoas da organização, de forma que gere um aumento na competitividade.

A principal vantagem competitiva das empresas baseia-se no capital humano, ou ainda no conhecimento tácito dos seus funcionários, que por sua vez, vem aumentando de forma considerável, seus patamares de educação e aspirações, de modo a se tornarem indivíduos organizacionais, que se realizam sendo criativos e aprendendo constantemente. (TERRA, 2001).

A Gestão do Conhecimento pode ser compreendida como o processo de criação de um ambiente de ensino-aprendizado, a partir da criatividade, do julgamento e do diálogo entre os indivíduos, que na sociedade do conhecimento necessitam desenvolver a proatividade, a flexibilidade, a multidisciplinaridade e a abertura para novos ensinamentos (SVEIBY, 1998).

Em termos gerais, podemos dizer que, a gestão do conhecimento requer análise situacional da empresa, assim como revisões contínuas do seu funcionamento, mas acima de tudo, estar presente na política e na cultura organizacional, considerando os contextos específicos de cada organização. Devido à importância que o conhecimento alcançou nos últimos anos, estudiosos, pesquisadores e administradores estão se unindo para desenvolver modelos de Gestão do Conhecimento para serem utilizados nas Instituições de Ensino Superior.

\subsection{Modelos para Gestão de Conhecimento em IES}

Segundo Stoner (1992), é mais fácil entender um processo complexo como a administração quando ele é descrito como uma série de partes separadas. As descrições desse tipo são conhecidas como modelos e têm sido usadas por estudantes e praticantes de administração durante décadas. Um 
modelo é a simplificação do mundo real, usada para demonstrar relacionamentos complexos em termos fáceis de serem entendidos. Modelos de Gestão de Conhecimento transformam o conhecimento existente, promovem vantagens competitivas e para as pessoas e organizações.

Para Sveiby (1998), a principal atividade nas organizações do conhecimento é justamente a sua transferência. Para Davenport e Prussak (1998) a transferência acontece naturalmente. O conhecimento é transferido nas organizações, quer gerenciemos ou não esse processo. Esta transferência é facilitada através dos modelos aplicados para gerenciar o conhecimento dos profissionais, através de processo formal e também de técnicas específicas que incentivam as trocas de informação e conhecimento, de forma espontânea entre as pessoas.

Um modelo de Gestão do Conhecimento desenvolvido para Instituições de Ensino Superior busca desenvolver estratégias específicas para incentivar as transferências de conhecimento de forma a gerar mais conhecimento, facilitar o trabalho do professor e aumentar a competitividade da organização.

Alguns modelos e pesquisas têm sido desenvolvidos por estudiosos e podem servir como guia para a implantação da Gestão do Conhecimento, a partir das experiências vividas na prática dentro das organizações. No contexto acadêmico há poucos estudos desenvolvidos, a seguir, alguns serão aqui apresentados neste artigo, destacando as características de cada um para conseqüentemente fazer uma comparação entre eles.

\subsection{Estudo 1 - Análise Situacional da Gestão de Conhecimento em uma Instituição de Ensino Superior por meio da Espiral do Conhecimento}

Felix (2003) desenvolveu um estudo em Instituições de ensino Superior visando descobrir quais os processos relacionados à Gestão do Conhecimento existentes no ambiente de ensinoaprendizagem de uma instituição de ensino superior, antes e depois do alinhamento estratégico dessa instituição.

Apesar de considerar autores como Stewart (1998), Davenport (1998), Von Krogh (2001), Edvinsson (1998), entre outros, a teoria de criação de conhecimento de Nonaka e Takeuchi (1997) é a base da aplicação do estudo.

A autora faz uma análise da Gestão do conhecimento em Instituição de Ensino Superior por meio da espiral do conhecimento proposta por Nonaka e Takeuchi (1997) para analisar se há Gestão do Conhecimento na prática docente e qual impacto a introdução do alinhamento estratégico, traz para este ambiente acadêmico. O objetivo foi verificar se a Gestão do Conhecimento estava sendo praticada na relação de aprendizagem existente entre os docentes e discentes de alguns departamentos de faculdades. 
Aborda um ambiente pouco estudado pela Gestão de Conhecimento analisando os tipos de transformação do conhecimento no contexto acadêmico, que pode ser expandido para a sociedade. Segundo a autora, a importância da produção do conhecimento interdisciplinar e interdepartamental para uma instituição de ensino superior vislumbra não só os grandes beneficiados, os alunos e os professores, potenciais produtores de conhecimentos, mas em maior escala, possibilita a alavancagem da gestão do conhecimento em toda a instituição, por meio de uma ampliação da estratégia utilizada para as demais áreas da organização. Em proporções maiores, torna possível a projeção da produção desses conhecimentos para o lado de fora dos muros da universidade, viabilizando a conversão dos conhecimentos acadêmicos produzidos em benefícios à sociedade. (FELIX, 2003).

A autora classifica as conversões de conhecimento encontradas em ações realizadas por professores, no tratamento das suas relações com outros docentes e com discentes, ou seja, em cada ação determina, em sua maioria, apenas um tipo de conversão de conhecimento.

No entanto, seria mais adequado dizer que as quatro formas de conversão devem ser consideradas em conjunto em cada uma dessas ações. Por exemplo, quando um professor dá uma aula expositiva, há, no mínimo, dois tipos de conversão: a externalização e internalização. Externalização que é a transformação do conhecimento tácito para explícito por parte do professor, quando ele procura dar exemplos da vida real para uma teoria existente, e a internalização (de explícito para tácito) por parte do aluno, quando ele aprende o que está sendo exposto. Se considerarmos uma aula dinâmica, onde haja integração entre as pessoas, acontece a socialização (tácito para tácito) e diálogo, discussão sobre o temas das aulas há a combinação das idéias (explícito para explícito).

$\mathrm{Na}$ verdade, em cada ação de construção do conhecimento, realizada pela instituição de ensino, contém todos os tipos de conversão da espiral do conhecimento, isto quer dizer que podemos encontrar mais de um tipo de conversão em cada uma das ações desenvolvidas.

Felix (2003) apesar de ter feito levantamento sobre a importância dos recursos humanos, em sua pesquisa trata apenas das relações pessoais entre professores e entre professores e alunos. Notase a ausência de outros atores que constituem a IES tais como diretores, coordenadores, pesquisadores e a também as relações com outras organizações e a sociedade como um todo que devem ser considerados como fatores indispensáveis para o sucesso da aplicação de um modelo. Os recursos tecnológicos também deveriam ser considerados, e este por sua vez, representa um fator importantíssimo para o desenvolvimento das atividades de qualquer organização nos dias de hoje, devido às facilidades que proporciona, é uma ferramenta de armazenamento, manuseio, troca e disseminação de informações e, consequentemente, construção de conhecimento. 


\subsection{Modelo 1 - Gestão do Conhecimento Científico no Contexto Acadêmico}

O modelo proposto por Leite (2006) associa os princípios da Gestão do Conhecimento dentro de uma IES à perspectiva dos processos de comunicação, especificamente da comunicação científica.

As universidades são responsáveis por grande parte da produção de conhecimento científico. O entendimento da dinâmica e de questões relacionadas à gestão de um tipo particular de conhecimento em um ambiente específico torna-se relevante para a construção e o amadurecimento de corpo teórico da gestão do conhecimento e da ciência da informação. (LEITE, 2006)

Uma vez que as universidades brasileiras, por meio dos programas de pós-graduação, são as responsáveis pela produção do conhecimento científico e tecnológico nacional, os seus pesquisadores e alunos de mestrado e doutorado constituem os protagonistas do processo de criação e compartilhamento do conhecimento científico. (LEITE, 2006). O destaque para a produção do conhecimento científico como algo integrado e não como um processo individual, ou seja, é resultado da colaboração entre cientistas.

O autor ressalta que a dinâmica das universidades requer o aproveitamento máximo da criação, armazenamento, compartilhamento e utilização do conhecimento, e que esta dinâmica pode ser otimizada pelos mecanismos e metodologias de Gestão de Conhecimento e que a criação de modelos para Instituição de Ensino Superior é relevante devido à função dessas instituições no que diz respeito ao o desenvolvimento do saber e da influência de descobertas científicas para melhoria na economia da sociedade. Porém, dá enfoque ao conhecimento científico, e a comunicação científica, como se a criação deste tipo de conhecimento acontecesse de forma separada dos demais conhecimentos e que o aproveitamento deste tipo de conhecimento se desse apenas por cientistas.

O conhecimento científico é formado pelo estudo e desenvolvimento de uma teoria e sua comprovação através de testes, realizados na própria sociedade, que validam a situação prática de determinado tema que está sendo pesquisado. É formado pela construção de saberes que envolvem elementos tais como a experiência de vida das pessoas e seu conhecimento tácito e explícito. Além da comunicação científica, os educadores utilizam a linguagem informal para que os alunos e sociedade em geral possam ter acesso à informação e possam aproveitar os serviços e pesquisas realizados pelas Instituições de Ensino Superior e não apenas para a comunidade acadêmica.

\subsection{Modelo 2 - Learning Organization numa IES: uma proposta empreendedora}

Felício Junior (2002) desenvolveu um modelo conceitual que faz uma relação entre as Instituições de Ensino Superior e as cinco disciplinas propostas por Peter Senge (1990): domínio pessoal, modelo mental, visão compartilhada aprendizagem em equipe e pensamento sistêmico. $\mathrm{O}$ 
autor complementa a proposta com a caracterização empreendedora e considera as interações com o meio ambiente e a abordagem sistêmica, assim como, sua importância para a expansão da aprendizagem organizacional e capacidade produtiva. Ressalta a relevância das Instituições de Ensino Superior criarem mecanismos que estimulem o comportamento empreendedor e também o papel destas instituições para formação de profissionais cada vez mais qualificados para o mercado de trabalho.

\begin{abstract}
"Acredita-se que as Instituições de Ensino Superior precisam formar um novo profissional. As organizações, hoje, preferem profissionais com incumbências e habilidades mais amplas. No contexto atual, o mercado de trabalho tem considerável tendência para o profissional empreendedor. E para se formar empreendedores, faz-se necessário que as Instituições de Ensino Superior saibam como criar mecanismos que estimulem o comportamento empreendedor, formando ou desenvolvendo indivíduos com estas características." (FELÍCIO JÚNIOR, 2002, p.60)
\end{abstract}

O autor considera o ambiente externo de uma forma geral, de modo que se nota a ausência de alguns elementos, tais como as perspectivas econômicas, ambientais e sociais da região, os concorrentes e o mercado de trabalho. Os alunos também não são considerados no modelo, assim como os métodos de ensino.

\title{
4. Análise Comparativa
}

Há alguns fatores que devem ser considerados quando se fala em desenvolver e aplicar a Gestão de Conhecimento nas organizações, principalmente quando o foco é o contexto acadêmico. Podemos citar alguns deles, como a estrutura e a tecnologia utilizada, o desenvolvimento dos profissionais, a utilização de uma abordagem sistêmica, o mercado de trabalho, as perspectivas econômicas, ambientais e sociais da região, os concorrentes diretos, as estratégias relacionadas ao conhecimento, os recursos humanos, a comunicação entre as pessoas, a inserção de uma política e cultura voltadas para renovação do conhecimento, práticas organizacionais empreendedoras, métodos de ensino inovadores e dinâmicos, interdisciplinaridade e aprendizagem contínua. Tais aspectos podem ser vistos na tabela 1, que ilustra a comparação destes fatores nos estudos realizados por Felix (2003), Leite (2006) e Felício Júnior (2002).

No estudo realizado encontramos em alguns casos, alguns destes elementos no referencial teórico pesquisado, porém na proposição do modelo de gestão de conhecimento para Instituições de ensino Superior os mesmos elementos citados na pesquisa da literatura como importantes para o funcionamento modelo não foram utilizados, como por exemplo, os concorrentes, o mercado de trabalho, as perspectivas econômicas, ambientais e sociais, além do empreendedorismo como postura para enfrentar as mudanças, os métodos de ensino inovadores e dinâmicos e a interdisciplinaridade das atividades. 
Tabela 1. Elementos principais de um Modelo de Gestão do Conhecimento em IES

\begin{tabular}{|c|c|c|c|}
\hline \multirow[b]{2}{*}{ FATORES } & \multicolumn{3}{|c|}{ ESTUDOS DESENVOLVIDOS } \\
\hline & $\begin{array}{c}\text { Estudo } 1 \\
\text { Felix }\end{array}$ & $\begin{array}{c}\text { Modelo } 1 \\
\text { Leite }\end{array}$ & $\begin{array}{c}\text { Modelo } 2 \\
\text { Júnior }\end{array}$ \\
\hline Estrutura/ tecnologia & Não & Não & Sim \\
\hline Recursos Humanos & Sim & Não & Sim \\
\hline Abordagem sistêmica & Sim & Não & Sim \\
\hline Estratégia & Sim & Não & Sim \\
\hline Comunicação & Sim & Sim & Sim \\
\hline Política/ cultura & Sim & Sim & Sim \\
\hline Empreendedorismo & Não & Não & Sim \\
\hline Métodos de Ensino e aprendizagem & Sim & Não & Não \\
\hline Concorrentes & Não & Não & Não \\
\hline Mercado de trabalho & Não & Não & Não \\
\hline $\begin{array}{l}\text { Perspectivas econômicas, ambientais e } \\
\text { sociais da região }\end{array}$ & Não & Não & Não \\
\hline Interdisciplinaridade & Não & Não & Sim \\
\hline Aprendizagem contínua & Não & Não & Não \\
\hline
\end{tabular}

Fonte: Autoria própria (2007).

O alinhamento estratégico da organização foi considerado por Felix (2003), no seu estudo como elemento para aumentar a eficiência. Apesar de ressaltar a importância do ambiente externo e da abordagem sistêmica, no referencial teórico, a autora não considera os concorrentes, mercado de trabalho e as perspectivas econômicas, ambientais e sociais de como variáveis do estudo. "Esta pesquisa considerou como variáveis, a gestão do conhecimento, representada pelas quatro conversões do conhecimento de Nonaka e Takeuchi (1997); o alinhamento estratégico, representado pelo objetivo, meta, indicador e ação; e algumas variáveis funcionais e pessoais dos participantes." (FELIX, 2002, p.59) Os recursos humanos considerados para melhoria do processo de aprendizagem são os professores e funcionários, isto é, os alunos não foram considerados. Nos questionários aplicados, a autora considera a cultura da organização e política, porém, aspectos como empreendedorismo, métodos de ensino inovadores e interdisciplinaridade não foram apreciados.

Os fatores considerados por Leite (2006) foram principalmente o ambiente acadêmico, as comunidades acadêmicas, a comunicação científica, a cultura e os processos de mapeamento, aquisição, organização e armazenagem, compartilhamento e criação de conhecimento. A abordagem sistêmica acontece considerando apenas o ambiente científico, como se este não estivesse inserido na sociedade e não sofresse influência do ambiente externo à organização como concorrentes, mercado de trabalho e as perspectivas econômicas, ambientais e sociais. Quanto aos 
aspectos relacionados às instituições de ensino superior, tais como, desenvolver o perfil empreendedor entre os alunos e funcionários, realizar atividades dinâmicas relacionando as diversas disciplinas entre si e desenvolver métodos de ensinos diferentes e inovadores, não foram encontrados no modelo.

Para Felício Júnior (2002), o elemento principal é o empreendedorismo aplicado às atividades das Instituições de ensino superior juntamente com a aprendizagem organizacional, por isso considera as 5 disciplinas de Senger. A abordagem sistêmica também está presente no modelo. A estratégia, os recursos humanos, a estrutura e a comunicação interna são desenvolvidas dentro das disciplinas de Senger, para serem aplicadas nas Instituições de ensino. O ambiente externo, apesar de ser considerado, é tratado de uma forma geral, não entrando em detalhes como as perspectivas sociais, econômicas e do ambiente, os concorrentes e o mercado de trabalho. Apesar de o autor considerar a interdisciplinaridade das atividades, não contempla os métodos de ensino e aprendizagem e nem considera os alunos como parte integrante do modelo.

\section{Conclusão}

As universidades são reconhecidas como responsáveis pela criação, armazenamento e disseminação de conhecimento entre as pessoas através das atividades de ensino, pesquisa e extensão. Um modelo de Gestão de Conhecimento desenvolve mecanismos capazes de agregar valor às atividades das IES. Desta forma, o ambiente acadêmico é um lugar ideal para aplicação de um modelo de Gestão de Conhecimento que proporcione um aumento na eficiência na criação de ciência, armazenamento, transferência e circulação de conhecimento e formação de profissionais.

O estudo identificou que apesar das Instituições de Ensino Superior possuírem um ambiente propício para aplicação de um modelo de Gestão do Conhecimento, ainda não existem muitas aplicações na área. Há poucos modelos de Gestão de Conhecimento desenvolvidos para serem aplicados no contexto acadêmico.

A análise dos modelos em estudo conduziu à percepção de alguns aspectos que devem ser considerados para a composição de um modelo de Gestão de Conhecimento que melhor caracterize a aplicabilidade no contexto acadêmico. Percebeu-se então a necessidade de um novo modelo de Gestão de Conhecimento que aplicasse os conceitos de forma a integrar as idéias citadas para complementar a fim de ser aplicados em Instituições de Ensino Superior.

O novo modelo a ser desenvolvido deve considerar que a prática que compõe a Instituição de Ensino Superior está diretamente relacionada com o comportamento das pessoas e o relacionamento com o ambiente. 
Há uma dificuldade em sintetizar os principais aspectos de um modelo de Gestão de Conhecimento para Instituição de Ensino Superior devido à turbulência do ambiente, por isso é preciso ressaltar a criatividade, compartilhamento das idéias, criação de processos sistemáticos, tudo isso associado aos processos operacionais e a estratégia da organização.

Estar atento ao que acontece no mercado para acompanhar as mudanças econômicas, tecnológicas ou sociais com o objetivo principal de dar satisfação aos clientes e ser competitivo é primordial para que o modelo funcione. Tecnologia é dos fatores mais citados como de extrema significância para utilização de Gestão de Conhecimento nas organizações. A utilização de softwares que guardem os dados e que tornem fácil o manuseio e compartilhamento de informações é imprescindível para o um aumento de competitividade. Há também a necessidade da inovação contínua no que diz respeito à aprendizagem e utilização de métodos dinâmicos de ensino, destacando a importância do desenvolvimento de um comportamento empreendedor por parte dos alunos, que deve ser incentivado através de atividades práticas dentro do ambiente acadêmico.

As quatro conversões de conhecimento propostas por Nonaka e Takeuchi (1997) poderiam ser aproveitadas para a aplicação de técnicas e métodos de ensino que envolva os conhecimentos explícitos e tácitos de forma a promover a criação de conhecimento no ambiente acadêmico para que as Instituições de Ensino Superior não só faça a transferência de conhecimentos teóricos, que mostrem a existência de modelos propostos, mas que também façam com que as pessoas aprendam a pensar e a fazer análise crítica e que possam se adaptar a qualquer mudança do ambiente.

\begin{abstract}
Nowadays, knowledge is an essential factor for the survival and success of organizations. Researchers have developed studies that result in the elaboration of concepts, systems and models of Knowledge Management that add value to the products and services offered, as well as increase the efficiency of the organizations, making them more competitive. This paper, the result of an exploratory research, introduces the definition of Knowledge Management and intends to identify indications that disclose the existence of elements that are in the process of Knowledge Management and collaborate with the improvement of the quality of education and the increase of productivity. The characteristics of some models of Knowledge Management in the academic context and their peculiarities are investigated in order to make a comparative analysis among some of them, as well as to originate a perspective that contributes to the creation of a new model of Knowledge Management for Tertiary Education Institutions.
\end{abstract}

Key-words: knowledge management; analysis of models; tertiary education institutions.

\title{
Referências
}

BUARQUE, C. A aventura da Universidade. São Paulo, ed UNESP, 1994.

BECKMAN, T. The current state of knowledge management. In; Liebowitz, J. Knowledge Management Handbook. Nova York, CRC, 1999.

DAVENPORT, T. e H., PRUSAK, L. Conhecimento Empresarial: como as organizações gerenciam seu capital intelectual. Rio de Janeiro: Campus, 1998. 
FELIX, P. Análise Situacional da gestão de conhecimento em uma Instituição de Ensino Superior por meio da espiral de conhecimento. Dissertação de Mestrado no Programa de Pós-graduação em Engenharia de Produção. Florianópolis, 2003.

HIBBARD, J. Knowing what we know. Information Week. Out. 1997.

JUNIOR, J. Learning Organization numa IES: uma proposta empreendedora. Dissertação de mestrado. Fundação Pedro Leopoldo, 2002.

LEITE, F. Gestão do conhecimento científico no contexto acadêmico : proposta de um modelo conceitual. Master's degree dissertation, Information Science, Universidade de Brasília. 2006.

MAXIMIANO, A. C. Introdução à Administração. São Paulo: Atlas, 2000.

MURRAY, P. C. New language for new leverage: the terminology of knowledge management. Disponível em http://www.ktic.com/topic6/13_term2.htm Acessado em abril de 2005.

NONAKA, I e TAKEUCHI, H. Criação de conhecimento na empresa: Como as empresas japonesas geram a dinâmica da inovação. Rio de Janeiro: Campus, 1997.

NONAKA, I. A empresa criadora de conhecimento. In: Gestão do Conhecimento: On Knowledge management. Harvard Business Rreview; Rio de Janeiro: Campus, 2000.

PETRASH, G. Dow's journey to a knowledge value management culture. European Management Journal. V.14 n.4, ago. 1996.

SENGER, P. A Quinta Disciplina: arte, teoria e prática da organização de aprendizagem. São Paulo: Best Seller, 1990.

STONER, J e FREEMAN E. Administração. Editora Prentice Hall do Brasil, Rio de janeiro, 1995.

SVEIBY, K. A Nova Riqueza das Organizações. Gerenciando e Avaliando Patrimônios de Conhecimento. Rio de Janeiro: Campus, 1998.

TERRA, C. Gestão do Conhecimento: Aspectos conceituais e estudo exploratório sobre as práticas de empresas brasileiras. In gestão estratégica do conhecimento - integrando conhecimento e competências / Maria Fleury, Oliveira Júnior. Editora Atlas, 2001.

TERRA, C. Definindo Gestão do Conhecimento. Disponível em http://www. terraforum.com.br. Acessado em Novembro de 2005.

VON KROGH, G; ICHIJO, K. e NONAKA, I. Facilitando a criação do conhecimento: reinventando a empresa como o poder da inovação contínua.Tradução de Afonso Celso da Cunha Serra. Rio de Janeiro: Campus, 2001.

WIIG, K. M. Knowledge management foundations; thinking about thinking - how pleople and organizations create, represent, and use knowledge. Arlington, Texas: Schema, 1993.

ZIMBARDO, P e EBBESEN, E. Influencing attitudes and changing behavior. Reading: Addison- Wesley, 1970.

\section{Dados dos autores:}

\section{Nome completo: Joyce Lene Gomes Cajueiro}

Filiação institucional: Centro Acadêmico do Agreste da Universidade Federal de Pernambuco

Departamento: Administração

Função ou cargo ocupado: Professor Adjunto 
Endereço completo para correspondência (bairro, cidade, estado, país e CEP): Av. Bernardo Vieira de Melo, 3883 Apt 1402 - Piedade, Jaboatão dos Guararapes, Pernambuco, Brasil. CEP: 54.420 .010 .

Telefones para contato: (81) 34683662, (81) 92623831

e-mail: joyce.cajueiro@hotmail.com

Nome completo: Abraham Benzaquen Sicsú

Filiação institucional: Fundação Joaquim Nabuco e Universidade Federal de Pernambuco.

Departamento: Engenharia de produção.

Função ou cargo ocupado: Pesquisador e professor

Endereço completo para correspondência (bairro, cidade, estado, país e CEP): Rua Luis Barbalho 120, AP 902, Boa Vista, Recife Pernambuco, Brasil. CEP: 50070-120

Telefones para contato: (81) 30736528 (81) 92324238

e-mail:sicsu@fundaj.gov.br

Nome completo: Ana Regina Bezerra Ribeiro

Filiação institucional: Faculdade Marista Recife

Departamento: Administração

Função ou cargo ocupado: Coordenadora e professora

Endereço completo para correspondência (bairro, cidade, estado, país e CEP): Rua Edson Alvares 115 Apto 1501- Casa Forte . Recife. Pernambuco. Brasil. Cep: 52061450

Telefones para contato: (81) 32655816 (81) 91525355

e-mail: anareginaribeiro@hotmail.com

Recebido para publicação em: 21/07/2009

Aceito para publicação em: 02/09/2009 